Proceedings of the 31st Annual Meeting of the Brazilian Embryo Technology Society (SBTE); Cabo de Santo Agostinho, PE, Brazil, August 17th to 19th, 2017.

\title{
Practical implications of sperm selection techniques for improving reproduction
}

\author{
Jane M. Morrell ${ }^{1,3}$, Arumugam Kumaresan ${ }^{1,2}$, Anders Johannisson ${ }^{1}$ \\ ${ }^{1}$ Department of Clinical Sciences/Division of Reproduction, Swedish University of Agricultural Sciences, SE-750 07 Uppsala, \\ Sweden. \\ ${ }^{2}$ Current affiliation: Theriogenology Laboratory, Animal Reproduction, Gynaecology \& Obstetrics, ICAR-NDRI-Southern \\ Regional Station, Adugodi, Bengaluru, 560030 Karnataka, India.
}

\begin{abstract}
Sperm selection techniques are needed to separate spermatozoa from seminal plasma and extender for in vitro fertilization (IVF) and to improve sperm quality for a range of assisted reproduction techniques. Apart from sperm washing, which removes some but not all of the seminal plasma, the selection techniques that are currently used are mainly swim-up and colloid centrifugation; filtration through Sephadex columns or glass wool is seldom used in the field. Although swimup can be used to prepare sperm samples for IVF, the low recovery rate and lack of selection for sperm quality other than motility make this technique ineffective for routine use. Colloid centrifugation is used to prepare semen for all types of assisted reproduction. The method has been scaled-up for voluminous ejaculates e.g. from stallion and boar, and scaled-down to accommodate small volumes of thawed semen (e.g. from bull). Sperm quality and fertility are improved, as shown in laboratory assays and in various fertility trials. Some normal spermatozoa are lost during the selection process but overall the advantages of improved longevity and fertility in the selected spermatozoa outweigh the disadvantages. Since spermatozoa are separated from bacteria in the ejaculate, it may be possible to reduce antibiotic usage in semen extenders. New applications of colloid centrifugation include extracting camelid spermatozoa from viscous seminal plasma, selecting spermatozoa with condensed chromatin (i.e. with fewer free thiols), and using the number of spermatozoa passing through the colloid as a diagnostic tool to indicate male fertility.
\end{abstract}

Keywords: chromatin integrity, colloid centrifugation, extended longevity, fertility, single layer centrifugation.

\section{Introduction}

Fertility in some species e.g. dairy cattle, has been declining in recent decades (Rodriguez-Martinez et al., 2007; López-Gatius, 2013). This decline may be partly due to negative energy balance in high yielding dairy cows (Diskin and Morris, 2008), but other factors may also be involved. For example, the number of bull spermatozoa included in an insemination dose has decreased, especially for sexed sperm samples (Seidel, 2014); two million spermatozoa may not be sufficient to give good pregnancy rates for all bulls (Andersson et al., 2004). In addition, changes have been made to freezing protocols, such as the avoidance of extenders containing egg yolk (Leite et al., 2010; Röpke et al., 2011) and increasing pre-freezing equilibration times (Leite et al., 2010; Shahverdi et al., 2014). In horse breeding, there has been a decrease in the foaling rate after artificial insemination (AI) to approximately $65 \%$ (Rota et al., 2004) but this could be due to the more widespread use of cooled shipped semen nowadays, or to a real decrease in fertility. The porcine AI industry still uses liquid (fresh) semen for AI in preference to cryopreserved semen (unless for export), because pregnancy rates and litter sizes are perceived to be better with fresh semen, despite considerable progress in developing cryopreservation protocols that result in more consistent sperm survival (Roca et al., 2006.)

One point is certain, however: good quality gametes are needed to produce good quality blastocysts (Vandaele and Van Soom, 2011; Morrell et al., 2016). Embryo quality, assessed using the guidelines established by the International Embryo Transfer Society (Stringfellow and Seidel, 1998), was linked with oocyte quality following embryo production in vitro in pigs (Chen et al., 2012), cattle (O'Hara et al., 2014; Saini et al., 2015), stallions (Colleoni et al., 2011 and human patients (Kurosawa et al., 2016).

Many studies have attempted to define the factors contributing to "good quality" spermatozoa: in vivo, bull sperm morphology was correlated with pregnancy rate (Attia et al., 2016; boar sperm fertility was linked independently with morphology, active mitochondria, beat cross frequency and oscillatory frequency (Schultze et al., 2013). The DNA integrity of stallion spermatozoa was correlated with pregnancy rate (Cuervo-Arango et al., 2009; Morrell et al., 2014c; Barrier Battut et al., 2016), whereas Underwood et al. (2010) linked the stresses of sex-sorting and re-freezing bull spermatozoa with low pregnancy rate. Ohlweiler et al. (2013) showed that there was no difference in fertilization rate when semen from bulls of low vigor was used to fertilize good and poor quality oocytes, whereas for semen of high vigor, the blastocyst rate was higher for good quality oocytes than for poor quality oocytes.

Sperm selection can be used to improve sperm quality (Morrell and Rodriguez-Martinez, 2009), which is the subject of this review, although oocyte quality and sperm/uterine interaction are vital components in fertilization and embryo production. In this review, the impact of sperm quality on fertility will be described briefly, followed by a discussion of sperm selection 
techniques, especially colloid centrifugation. After describing the practical uses of colloid centrifugation, the implications of sperm selection by this method for animal breeding will be presented.

\section{Relationship between sperm quality and fertility}

Sperm quality is a term used to define the predicted functionality of a sperm population. It incorporates a number of components that affect the ability of the spermatozoa to move through the reproductive tract to locate and interact with the oocyte. These factors include sperm motility, morphology, membrane integrity, degree of apoptosis, acrosome integrity, capacitation, mitochondrial membrane potential, chromatin integrity, chromatin maturity, production of reactive oxygen species, and ability to bind to the zona pellucida. Relationships have been found between a number of these parameters and fertility, either in vitro or following $\mathrm{AI}$; examples have been described in detail in another review (Morrell and RodriguezMartinez, 2009) and are summarized in Table 1.

Table 1. Examples of the relationship between parameters of sperm quality and fertility in various species.

\begin{tabular}{ll}
\hline \multicolumn{1}{c}{ Parameter } & \multicolumn{1}{c}{ Reference } \\
\hline Normal morphology (cattle) & Wiltbank and Parrish, 1986; Menon et al., 2011 \\
Normal morphology (pigs) & Tsakmakidis et al., 2010 \\
Normal morphology (horses) & Parlevliet et al., 1999; Kavak et al., 2004 \\
Chromatin integrity (boars) & Lopez Fernandez et al., 2008 \\
Chromatin integrity (horses) & Love and Kenny, 1998 \\
Chroamtin integrity (bulls) & Karoui et al., 2012 \\
Acrosome integrity (buffalo) & Ahmed et al., 2003 \\
Acrosome integrity (bulls) & Al-Mahkzoomi et al., 2008 \\
Plasma membrane integrity (bulls) & Christiansen et al., 2011 \\
Mitochondrial membrane potential & Pena et al., 2009 \\
Reactive oxygen species & Aitken et al., 2012 \\
\hline
\end{tabular}

\section{Sperm selection techniques}

Since sperm quality appears to affect fertility and therefore reproduction, selecting sperm subpopulations with certain characteristics known to be associated with fertility should lead to increased reproductive efficiency. Several sperm selection techniques are available, as reviewed previously (Morrell et al., 2016). The purpose of sperm selection techniques is to separate specific sperm sub-populations from the ejaculate and to separate them from seminal plasma. In this respect, laboratory procedures mimic events occurring in the female reproductive tract, whereby normal spermatozoa interact with parts of the female reproductive tract whereas abnormal spermatozoa do not (Suarez, 2007). The hypothesis is that this interaction with the female reproductive tract enables unsuitable spermatozoa to be removed, thereby prevented them from reaching the oocyte. Since laboratory selection techniques mimic a biological activity, they are known as "biomimetic".

Selection can be done by migration e.g. swimup, by filtration e.g. through Sephadex or glass wool, or by colloid centrifugation. Cell sorting can be done in a flow cytometer or magnetic cell sorter, but these techniques are mostly too time-consuming to be used routinely, except on the larger semen collection stations. Swim-up is used mostly to prepare spermatozoa for in vitro fertilization or ICSI; colloid centrifugation is used for these applications and also to prepare semen for AI, especially the scaled-up versions (Morrell et al., 2009b), and for cryopreservation (Hoogewijs et al., 2011).

In the swim-up technique, collection medium is pipetted on top of extended semen in a centrifuge tube, which is then placed in an incubator. Motile spermatozoa move away from the rest of the sample and can be harvested from the collection medium. However, selection is only for sperm motility; there is no selection for normal morphology or chromatin integrity (Somfai et al., 2002). The procedure takes $45-60 \mathrm{~min}$ and results in the recovery of approximately $10 \%$ of the spermatozoa. Whilst such small sperm numbers may be adequate for IVF, they are clearly impractical when preparing spermatozoa for AI.

In filtration, spermatozoa pass through a column of Sephadex or glass wool; spermatozoa with damaged membranes or defective acrosomes bind to the Sephadex and are retained on the column (Bussalleu et al., 2008). Although a higher recovery rate is achieved with this technique than with swim-up, sperm quality may only be improved if there is a high proportion of damaged spermatozoa in the original sperm sample. This technique is used mainly in the laboratory or for research: there are no reports of its routine use under field conditions.

Colloid centrifugation involves layering extended semen over colloid e.g. silane-coated silica, in a centrifuge tube, followed by centrifugation for $20 \mathrm{~min}$ at a low g force, typically $300 \mathrm{~g}$. After centrifugation, the sperm pellet contains mostly highly motile, morphologically normal spermatozoa with intact membranes and good chromatin integrity (Johannisson et al., 2009) that are not producing hydrogen peroxide (Morrell et al., 2017). Immotile or damaged spermatozoa are retained at the semen:colloid interface while seminal plasma remains above the colloid (boar semen; Kruse et al., 2011). This technique has been used to prepare stallion spermatozoa in the field for AI (Morrell et al., 2011a, 2014b) as well as bull and boar spermatozoa for IVF (Thys et al., 2009; Sjunnesson et al., 2013) or stallion spermatozoa for ICSI (Colleoni et al., 2011. Single Layer centrifugation (SLC) is a 
modification of density gradient centrifugation (DGC) in which only one layer of colloid is used i.e. no density gradient is present. The advantage of SLC is that it is easier to use than DGC, requiring fewer steps in the preparation, and it can be scaled-up to process large volumes of semen e.g. $15-20 \mathrm{ml}$ per $50 \mathrm{ml}$ tube for stallion semen (Morrell et al., 2009b) or up to $150 \mathrm{ml}$ per $500 \mathrm{ml}$ tube for boar semen (Morrell et al., 2011b). It can also be scaled-down to process only $250 \mu \mathrm{l}$ thawed bull semen on $1 \mathrm{ml}$ colloid in a $15 \mathrm{ml}$ tube (Abraham et al., 2016); a higher sperm yield is obtained if a $15 \mathrm{ml}$ centrifuge tube is used rather than a small (1.5 $\mathrm{ml})$ tube.

\section{Practical uses of colloid centrifugation}

For in vitro fertilization or intracytoplasmic sperm injection

When preparing spermatozoa for IVF or ICSI it is important to remove seminal plasma, which contains decapacitating factors, and to replace the cryopreservation medium with capacitating medium or fertilization medium. The simplest way to do this is by centrifugation to pellet the spermatozoa, followed by resuspension of the sperm pellet in the new medium. However, all the spermatozoa, including the dead and dying or abnormal spermatozoa, will appear in the pellet since there is no selection for normal spermatozoa with this method. Such centrifugation can also cause damage to intact spermatozoa and may result in the release of reactive oxygen species that attack sperm membranes and DNA.

An important consideration for IVF or ICSI is that the selection of normal spermatozoa that occurs in the female reproductive tract is not present (Suarez, 2007) potentially allowing abnormal spermatozoa or those with damaged chromatin to fertilize the oocyte (Rath et al., 2008). Although the oocyte is fertilized and activated, there may be problems due to the damaged chromatin during embryo development or even after implantation (Katari et al., 2009; Evenson, 2016). It can be speculated that this may be one of the reasons why so many conceptuses or early pregnancies are lost in cattle, since approximately $90 \%$ of dairy cow oocytes are fertilized but less than half of these result in the birth of a calf (Diskin and Morris, 2008; LopezGatius, 2013).

Karoui et al. (2012 observed that sperm DNA fragmentation (chromatin dispersion test) could be used to identify the least fertile bulls in a cohort study. Evenson (2016) reviewed many studies on the association between \%DFI (evaluated by the Sperm Chromatin Structure Assay) and fertility; he reported threshold values for \%DFI in various species above which there was likely to be an impact on fertility as: pigs $6 \%$, bulls $10-20 \%$, horses $28 \%$, humans $25-30 \%$.

\section{For artificial insemination}

The ejaculate contains a heterogeneous population of spermatozoa at different stages of maturity, some of which may be abnormal. These abnormal spermatozoa are included in the insemination dose and thus may reduce the number of normal spermatozoa reaching the oviducts to below the threshold required in order to ensure fertilization. This is particularly important for cattle where the number of spermatozoa in the insemination dose has been reduced to a small fraction of those in the original ejaculate. Alternatively, spermatozoa with damaged chromatin may compete with those with intact chromatin to fertilize the oocyte. Selecting normal spermatozoa with good chromatin integrity would be an obvious way of circumventing this problem.

Does colloid centrifugation really overcome this problem? This question can be answered using stallion spermatozoa as an example. Usually stallion semen is inseminated within 24-36 $\mathrm{h}$ after semen collection, being stored in the meantime at approximately $6^{\circ} \mathrm{C}$ (Varner et al., 1987). There are occasional reports of pregnancies being achieved after longer periods of cooled storage but this is not usual within the equine breeding industry and not feasible for some stallions. For some stallion semen, it is not possible to cool it at all; it must be inseminated within a short time of collection in order to obtain pregnancies. Preparing stallion semen by SLC allows even spermatozoa from these so-called "poor coolers" to be cooled and transported to other stud farms for insemination after $24 \mathrm{~h}$ (Morrell et al., 2011a). Chromatin integrity is higher in SLC-selected samples, and this integrity is maintained during storage (Table 2). Semen from normal stallions, processed by SLC, survive for at least $96 \mathrm{~h}$ after semen collection (Richter et al., 2016) and have good fertilizing ability (Lindahl et al., 2012. In a controlled trial inseminating mares with cooled sperm samples $24 \mathrm{~h}$ after semen, a higher number of mares were pregnant with the SLC-selected spermatozoa $(54 / 78)$ than with control (unselected; 37/82) sperm samples (Morrell et al., 2014b). The SLCselected samples showed an increased proportion of morphologically normal, membrane-intact spermatozoa with good chromatin integrity than control samples (Morrell et al., 2009a; 2010). Interestingly, production of hydrogen peroxide is markedly decreased in these SLC-selected samples (Morrell et al., 2017), which may contribute to the longer survival and retention of fertilizing capacity compared to control sperm samples. In vitro fertilizing capacity is also enhanced in SLCselected sperm samples; the number of SLC-selected boar spermatozoa used for IVF had to be drastically reduced to avoid polyspermy (Sjunnesson et al., 2013). The SLC preparation technique has also been used to prepare stallion spermatozoa for ICSI (Table 3). 
Morrell et al. Sperm selection methods for improved reproduction.

Table 2. DNA fragmentation index $(\% \mathrm{DFI})$ in stallion sperm samples prepared by Single Layer Centrifugation compared to uncentrifuged controls immediately after preparation and again after $24 \mathrm{~h}$ storage at $6^{\circ} \mathrm{C}$.

\begin{tabular}{lcc}
\multicolumn{1}{c}{ Time after preparation (number) } & Uncentrifuged & SLC \\
\hline $0 \mathrm{~h}(\mathrm{n}=144)$ & $15.1 \pm 9.3$ & $10.2 \pm 8.9$ \\
$24 \mathrm{~h}(\mathrm{n}=77)$ & $26.0 \pm 14.0$ & $13.9 \pm 14.0$ \\
\hline
\end{tabular}

Modified from Morrell et al. (2010).

Table 3. Blastocyst development after intracytoplasmic sperm injection of equine oocytes, using spermatozoa prepared by colloid centrifugation.

\begin{tabular}{lccc}
\hline \multicolumn{1}{c}{ Treatment } & $\begin{array}{c}\text { No. injected } \\
\text { oocytes }\end{array}$ & No. blastocysts & $\begin{array}{c}\text { Development to blastocyst } \\
(\%)\end{array}$ \\
\hline DGC fertile (control) & 17 & 4 & 21 \\
SLC fertile (control) & 21 & 4 & 19 \\
DGC infertile & 104 & 15 & 21 \\
SLC infertile & 107 & 21 & 30 \\
\hline
\end{tabular}

Note: DGC = density gradient centrifugation, SLC = Single Layer Centrifugation; fertile and infertile refer to the fertility status of the two stallions used as a source of spermatozoa. From Colleoni et al. (2011).

\section{In cryopreservation}

Stallion spermatozoa selected by SLC show better cryosurvival than non-selected sperm samples (Hoogewijs et al., 2011) and may have longer post-thaw survival (Hoogewijs et al., 2012). This latter attribute may also be a result of decreased hydrogen peroxide production in the thawed sperm samples, although reactive oxygen species production was not measured in their study. However, in studies with boar spermatozoa, SLC-selected spermatozoa were found to produce less hydrogen peroxide than non-selected spermatozoa (Martinez-Alborcia et al., 2012); and showed increased cryosurvival (Martinez-Alborcia et al., 2012, 2013). A higher mitochondrial membrane potential was observed in frozen-thawed SLC-selected bull spermatozoa compared to controls (Nongbua et al., 2017). In a previous study with fresh bull spermatozoa, chromatin integrity was significantly better in SLC-selected samples compared to controls (Goodla et al., 2014).

\section{Removal of bacteria}

When considering semen quality, one factor that is often overlooked is the bacterial content of the semen (Morrell and Wallgren, 2014). Almost all ejaculates become contaminated with bacteria during semen collection and subsequent handling (Maes et al., 2008); a negative correlation has been found between bacterial contamination above a certain threshold and litter size in pigs (Maroto Martin et al., 2010). Therefore, antibiotics are added to semen extenders to control microbial growth. Nowadays, there is increasing awareness of antibiotic resistance arising from the widespread use of antibiotics, both in human and veterinary medicine (Catry et al., 2010). Genes for resistance spread between bacteria in different host species (Johansson et al., 2004). There are anecdotal accounts that many bacteria found in semen are resistant to the antibiotics that are added to semen extenders; therefore the widespread practice of adding antibiotics to semen extenders may contribute to the problem of antibiotic resistance. An alternative to antibiotics would be to physically separate spermatozoa from bacteria in semen. Colloid centrifugation removes, or substantially reduces, bacterial contamination in boar (Morrell and Wallgren 2011) and stallion semen (Morrell et al., 2014a). Such an alternative would seem to be an excellent solution to avoid the further development of antimicrobial resistance, particularly when one considers the scale of usage of antibiotic-containing extenders in the semen production industry.

\section{Recent developments with colloid centrifugation}

\section{Camelid semen}

Processing camelid semen is known to be a problem due to the high viscosity of the seminal plasma, which also prevents penetration of cryoprotectants into spermatozoa during freezing. One solution to this problem has been to use enzymes to break down the viscous seminal plasma, although there is concern that the enzymes might damage the spermatozoa. Llama semen processed SLC after treatment with enzymes resulted in the production of hatched blastocysts in IVF (Trassoras et al., 2012). Obviously it would be preferable to avoid enzymes completely, if at all possible, but separating the spermatozoa from the enzyme-containing medium after a short exposure appears to be an option. A further development is that dromedary camel semen, processed by SLC after mechanical breakdown of the viscous seminal plasma by gentle pipetting, survived freezing and thawing (Malo et al., 2017), and pregnancies have been obtained.

\section{Indicators of fertility}

It was reported previously that the number of spermatozoa passing through the colloid could be used as an indicator of potential fertility of the original ejaculate. This was found to be the case for stallions where the yield of spermatozoa after SLC was found to be related to the pregnancy rate of mares inseminated with cooled semen from the same ejaculates (Morrell et al., 2014b). In a similar study with boar semen, the number of spermatozoa passing through the colloid was 
related to the pregnancy rate in inseminated sows (Martinez-Alborcia et al., 2017). Thus, SLC could be used to provide a rapid means of identifying less highly fertile boars without the necessity of waiting for the outcome of AI trials, to allow their removal from the breeding pool at an early stage.

\section{Additional marker of chromatin integrity}

Chromatin integrity can be evaluated either by means of the Sperm Chromatin Structure Assay or by the Chromatin Dispersion Assay. However, there are other methods of evaluating chromatin structure, e.g. by measuring free thiols (as an indicator of lack of disulfide bond formation). Preliminary studies with bull spermatozoa indicate that SLC-selected sperm samples have fewer free thiols than control samples (Fig. 1). If this result is confirmed in a larger sample size, it could indicate that SLC selects for mature spermatozoa with highly condensed chromatin.

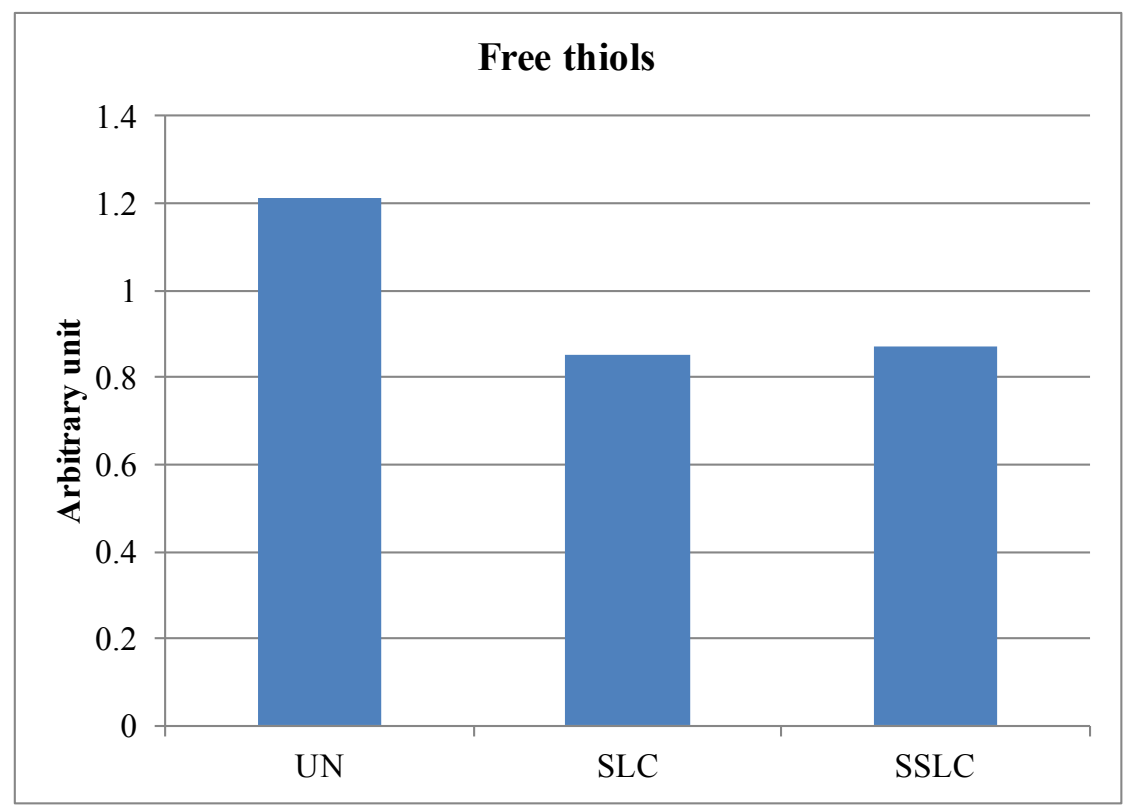

Figure 1. free thiols in SLC and control bull sperm samples. Note: un = control (uncentrifuged); SLC = single layer centrifugation; SSLC $=$ stored for $24 \mathrm{~h}$ befor SLC.

\section{Implications of colloid centrifugation to animal breeding}

As described in the preceding section, colloid centrifugation has a number of practical uses; there are many advantages and some disadvantages to the technique, as summarized in Table 4. The main advantages are the improved sperm quality and fertilizing ability, which are retained for longer in the selected sperm samples than in unselected ones. However, since only good quality spermatozoa are selected, there can be a considerable reduction in sperm numbers during processing, depending on the quality of the original ejaculate (Hoogewijs et al., 2011; MartinezAlborcia et al., 2013), and some good quality spermatozoa may be lost. The advantages outweigh the disadvantages: the vast majority of the spermatozoa recovered are functional and retain this functionality because they are not in the presence of damaged spermatozoa and hydrogen peroxide. Since the spermatozoa are highly fertile, it may be possible to reduce the number in the insemination dose. The small volume of colloid needed for the scaled-down version is economically more attractive than the larger volume when preparing spermatozoa for IVF or ICSI.

The ability to separate spermatozoa from seminal plasma without causing damage opens up the possibility of manipulating semen samples to obtain desirable attributes (de Graaf et al., 2008). This could involve substituting seminal plasma from an animal of low fertility (or poor freezability) with that from a high fertility (or good freezability) male (Morrell et al., 2014d; Nongbua et al., 2016a).

The possibility of separating spermatozoa from bacteria without the use of antibiotics has the potential to be of considerable importance, to slow the development of antimicrobial resistance. The animal breeding industry uses very large amounts of antibiotics at present, and there is a need to reduce this nontherapeutic use, which should be possible with SLC. The industry would also like to have more reliable indicators of a male's potential fertility; by extrapolating from the results with stallion semen, SLC appears to offer such an indicator 
Morrell et al. Sperm selection methods for improved reproduction.

Table 4. Advantages and disadvantages of colloid centrifugation for sperm preparation.

\begin{tabular}{|c|c|}
\hline Advantages & Disadvantages \\
\hline $\begin{array}{l}\text { Species-specific colloid formulations are available } \\
\text { commercially }\end{array}$ & Colloid is expensive \\
\hline Technique is not complicated; little training is required & $\begin{array}{l}\text { Centrifuge required; } 20 \text { minute centrifugation } \\
\text { time }\end{array}$ \\
\hline Highly fertile spermatozoa recovered & Some good quality spermatozoa are lost \\
\hline $\begin{array}{l}\text { Motile, morphologically normal spermatozoa with intact } \\
\text { membranes are selected }\end{array}$ & \\
\hline $\begin{array}{l}\text { Spermatozoa retain fertilizing ability for longer than } \\
\text { unselected spermatozoa }\end{array}$ & \\
\hline $\begin{array}{l}\text { Spermatozoa with damaged DNA are removed } \rightarrow \text { embryo } \\
\text { development not impeded }\end{array}$ & \\
\hline Fewer spermatozoa may be needed in insemination dose & \\
\hline $\begin{array}{l}\text { Reduction in bacterial contamination can obviate the need } \\
\text { for antibiotics }\end{array}$ & \\
\hline May be used as an indicator of fertility & \\
\hline $\begin{array}{l}\text { Can be used to extract camel spermatozoa from viscous } \\
\text { seminal plasma }\end{array}$ & \\
\hline $\begin{array}{l}\text { May select spermatozoa with highly condensed chromatin } \\
\text { (fewer free thiols) }\end{array}$ & \\
\hline
\end{tabular}

\section{Conclusions}

Sperm selection techniques are used when preparing sperm samples for assisted reproduction. Single layer centrifugation is especially beneficial since it selects the best quality spermatozoa from the rest of the ejaculate and also separates them from contaminating bacteria. The technique is simple to use, even in the field, although some good quality spermatozoa are also lost during processing. The technique shows promise for handling semen from unusual species such as camelids, and may be used in other contexts such as to differentiate between elite males and less highly fertile ones. It has advantages over migration or filtration techniques in selecting for sperm chromatin integrity.

\section{Acknowledgments}

JMM and AJ were supported by a grant from the Swedish Farmers' Association (grant number 1330039). AK received a "Lal Bahadur Shastri Young Scientist Award" from the Indian Council of Agricultural Research.

\section{References}

Abraham MC, Johannisson A, Morrell JM. 2016. Effect of sperm preparation on development of bovine blastocyst in vitro. Zygote, 24:825-830.

Ahmed Z, Anzar M, Shahab M, Ahmad N, Andrabi SMH. 2003. Sephadex and sephadex ion-exchange filtration improves the quality and freezability of lowgrade buffalo semen ejaculates. Theriogenology, 59:1189-1202.

Aitken RJ, De Iuliis GN, GibbZ, Baker MA. 2012.

New horizons on an old landscape - oxidative stress, DNA damage and apoptosis in the male germ line. Reprod Domest Anim, 47(suppl. 4):7-14.

Al-Makhzoomi A, Lundeheim N, Håård $M$,
Rodriguez-Martinez H. 2008. Sperm morphology and fertility in progeny-tested AI dairy bulls in Sweden. Theriogenology, 70:682-691.

Andersson M, Taponen J, Koskinen E, Dahlbom M. 2004. Effect of insemination with doses of 2 or 15 million frozen-thawed spermatozoa and semen deposition site on pregnancy rate in dairy cows. Theriogenology, 61:1583-1588.

Attia S, T Katila T, Andersson M. 2016 The effect of sperm morphology and sire fertility on calving rate of Finnish Ayrshire AI bulls. Reprod Domest Anim, 51:5458.

Barrier Battut I, Kempfer A, Becker J, Lebailly L, Camugli S, Chevrier L. 2016. Development of a new fertility prediction model for stallion semen, including flow cytometry Theriogenology 86:1111-1131.

Bussallou E, Pinart E, Rivera MM, Arlas X, Briz M, Sancho S, Garcia-Gil N, Bassols J, Prunedo A, Yeste M, Casas I, Rigau, T, Rodriguez-Gil JE, Bonet S. 2008. Effects of filtration of semen doses from subfertile boars through neuter Sephadex columns. Reprod Domest Anim 43:48-52.

Catry B, van Duijkere E, Pomba MC, Greko C, Moreno MA, Pyörälä, S, Ruzauskas M, Sanders P, Threlfall EJ, Ungemach F, Törnele K, MunozMadero C, Torren-Edo J, Scientific Advisory Group on Antimicrobials (SAGAM). 2010. Reflection paper on MRSA in food-producing and companion animals: epidemiology and control options for human and animal health. Epidemiol Infect, 138:626-644.

Chen TY, Stott Pathorn RZ, Bouwman EG, Langendijk P. 2012. Undernutrition during early follicle development has irreversible effects on ovulation rate and embryos Reprod Fertil Dev, 24:886892

Christiansen P, Labouriau R, Birck A, Boe-Hansen GB, Pedersen J, Borchersen S. 2011. Relationship among seminal quality measures and field fertility of young dairy bulls using low-dose inseminations. J Dairy Sci, 94:1744-1754. 
Colleoni S, Lagutina I, Rodriguez-Martinez $\mathbf{H}$, Lazzari G, Galli C, Morrell JM. 2011. New techniques for selecting spermatozoa for equine assisted reproduction. J Equine Vet Sci, 31:536-541.

Cuervo-Arango J, Aguilar J, Newcombe JR. 2009. Effect of type of semen, time of insemination relative to ovulation and embryo transfer on early equine embryonic vesicle growth as determined by ultrasound Theriogenology, 71:1267-1275.

de Graaf SP, Leahy T, Marti J, Evans G, Maxwell, WMC. 2008. Application of seminal plasma in sexsorting and sperm cryopreservation. Theriogenology, 70:1360-1363.

Diskin MG, Morris DG. 2008. Embryonic and early foetal losses in cattle and other ruminants. Reprod Domest Anim, 43(suppl. 2):260-267.

Evenson DP. 2016. The Sperm Chromatin Structure Assay (SCSA $\left.{ }^{\circ}\right)$ and other sperm DNA fragmentation tests for evaluation of sperm nuclear DNA integrity as related to fertility. Anim Reprod Sci, 169:56-75.

Goodla L, Morrell JM, Yusnizar Y, Stålhammar H, Johannisson A. 2014. Quality of bull spermatozoa after preparation by single layer centrifugation. J Dairy Sci, 97:2204-2212.

Hoogewijs M, Morrell JM, Van Soom A, Govaere J, Johannisson A, Piepers P, De Schauwer C, de Kruif A, De Vliegher S. 2011. Sperm selection using single layer centrifugation prior to cryopreservation can increase post thaw sperm quality in stallions. Equine Vet $J, 43$ (suppl. 40):35-41.

Hoogewijs M, Piepers S, Govaere J, De Schauwer C, de Kruif, A Morrell JM. 2012. Sperm longevity following pre-freeze sperm selection. $J$ Equine Vet $S c i$, 32:489. doi: http://dx.doi.org/10.1016/j.jevs.2012.06.048

Johannisson A, Morrell JM, Thorén J, Jonsson M, Dalin A-M, Rodriguez-Martinez H. 2009. Colloidal centrifugation with Androcoll-E ${ }^{\mathrm{TM}}$ prolongs stallion sperm motility, viability and chromatin integrity. Anim Reprod Sci, 116:119-128.

Johansson A, Greko C, Engström BE, Karlsson M 2004. Antimicrobial susceptibility of Swedish, Norwegian and Danish isolates of Clostridium perfringens from poultry, and distribution of tetracycline resistance genes. Vet Microbiol, 99:251-257.

Karoui S, Díaz C, González-Marín C, Amenabar ME, Serrano M, Ugarte E, Gosálvez J, Roy R, López-Fernández C, Carabaño MJ. 2012. Is sperm DNA fragmentation a good marker for field AI bull fertility? J Anim Sci, 90:2437-2449.

Katari S, Turan N, Bibikova M, Erinle O, Chalian R, Foster M, Gaughan JP, Coutifaris C, Sapienza C. 2009. DNA methylation and gene expression differences in children conceived in vitro or in vivo. Hum Mol Genet, 18:3769-3778.

Kavak A, Lundeheim N, Aidnik M, Einarsson S. 2004. Sperm morphology in Estonian and Tori breed stallions. Acta Vet Scand. 45:11-8.

Kruse R, Dutta PC, Morrell JM. 2011. Colloid centrifugation removes seminal plasma and cholesterol from boar spermatozoa. Reprod Fertil Dev, 23:858-865. Kurosawa H, Utsunomiya H, Shiga N, Takahashi A, Ihara M, Ishibashi M, Nishimoto M, Watanabe Z,
Abe H, Kumagai J, Terada Y, Igarashi H, Takahashi T, Fukui A, Suganuma R, Tachibana M, Yaegashi N. 2016. Development of a new clinically applicable device for embryo evaluation which measures embryo oxygen consumption. Hum Reprod, 31:2321-2330.

Leite TG, Vale-Filho VR, Arruda RP, Andrade AF, Emerick LL, Zaffalon FG, Martins JA,Andrade VJ. 2010. Effects of extender and equilibration time on post-thaw motility and membrane integrity of cryopreserved Gyr bull semen evaluated by CASA and flow cytometry. Anim Reprod Sci, 120:31-38.

Lindahl J, Dalin A-M, Stuhtmann G, Morrell JM. 2012. Stallion spermatozoa selected by Single Layer Centrifugation are capable of fertilization after storage for up to $96 \mathrm{~h}$ at $6^{\circ} \mathrm{C}$ prior to artificial insemination. Acta Vet Scand, 54:40-45.

Lopez-Fernandez C, Perez-Llano B, Garcia-Casado P, Sala R, Gosalbez A, Arroyo F, Fernandez JL, Gosalvez J. 2008. Sperm DNA fragmentation in a random sample of the Spanish boar livestock. Anim Reprod Sci, 103:87-98.

López-Gatius F. 2013. Approaches to increase reproductive efficiency in artificially inseminated dairy cows. Anim Reprod, 10:143-147.

Love CC, Kenney RM. 1998. The relationship of increased susceptibility of sperm DNA to denaturation and fertility in the stallion. Theriogenology, 50:955-972. Maes D, Nauwynck H, Rijsselaere T, Mateusen B, Vyt P, de Kruif A, Van Soom A. 2008. Diseases in swine transmitted by artificial insemination: an overview. Theriogenology 70:1337-1345.

Malo C, Crichton E, Morrell JM, Pukazhenthi B, Skidmore J. 2017. Single layer centrifugation of fresh dromedary camel semen improves sperm quality and in vitro fertilization capacity compared with simple sperm washing. Reproduction in Domestic Animals In Press

Maroto Martin LO., Cruz Munoz E, de Cupere F, van Driessche E, Echemendia-Blanco D, Machado Rodriguez J, Beeckmans S. 2010. Bacterial contamination of boar semen affects the litter size. Anim Reprod Sci, 120:95-104.

Martinez-Alborcia MJ, Morrell JM, Parrilla I, Barranco I, Vázquez JM, Martinez EA, Roca J. 2012. Improvement of boar sperm cryosurvival by using single-layer colloid centrifugation prior to freezing. Theriogenology, 78:1117-1125.

Martinez-Alborcia MJ, Morrell JM, Barranco I, Maside C, Gil MA, Parrilla I, Vazquez JM, Martinez EA, Roca J. 2013. Suitability and effectiveness of single layer centrifugation using Androcoll-P in the cryopreservation protocol for boar spermatozoa. Anim Reprod Sci, 140:173-179.

Menon AG, Barkema HW, Wilde R, Kastelic JP, Thundathil JC. 2011. Associations between sperm abnormalities, breed, age, and scrotal circumference in beef bulls. Can J Vet Res, 75:241-247.

Morrell JM, Johannisson A, Dalin A-M, RodriguezMartinez H. 2009a. Morphology and chromatin integrity of stallion spermatozoa prepared by density gradient and single layer centrifugation through silica colloids. Reprod Domest Anim, 44:512-517. 
Morrell JM, Johannisson A, Dalin A-M, RodriguezMartinez H. 2009b. Single Layer Centrifugation with Androcoll ${ }^{\mathrm{TM}}$-E can be scaled-up to allow large volumes of stallion ejaculate to be processed easily. Theriogenology, 72:879-884.

Morrell JM, Rodriguez-Martinez H. 2009. Biomimetic techniques for improving sperm quality in animal breeding: a review. Open Androl J, 1:1-9. doi: 10.2174/1876827X00901010001.

Morrell JM, Rodriguez-Martinez H, Johannisson A. 2010. Single Layer Centrifugation of stallion spermatozoa consistently selects the most robust spermatozoa from the rest of the ejaculate in a large sample size: data from 3 breeding seasons. Equine Veterinary Journal 42: 579-585.

Morrell JM, Mari G, Kutvölgyi G, Meurling S, Iacono E, Mislei B, Rodriguez-Martinez H. 2011a. Spermatozoa from stallion ejaculates processed by Single Layer Centrifugation with Androcoll ${ }^{\mathrm{TM}}$-E are capable of fertilization after artificial insemination. Reprod Domest Anim, 46:642-645.

Morrell JM, van Wienen M, Wallgren M. 2011b. Single Layer Centrifugation can be scaled-up further to process up to ml50semen . ISRN Vet Sci, 2011:art.183412. doi:10.5402/2011/183412.

Morrell JM, Wallgren M. 2011. Removal of bacteria from boar ejaculates by Single Layer Centrifugation can reduce the use of antibiotics in semen extenders. Anim Reprod Sci, 123:64-69.

Morrell JM, Klein C, Lundeheim N, Erol E, Troedsson MHT. 2014a. Removal of bacteria from stallion semen by colloid centrifugation. Anim Reprod Sci, 145:47-53.

Morrell JM, Richter J, Martinsson G, Stuhtmann G, Hoogewijs M, Roels K, Dalin A-M. 2014b. Pregnancy rates are higher after artificial insemination with cooled stallion spermatozoa selected by Single Layer Centrifugation than with control semen doses. Theriogenology, 82:1102-1105.

Morrell JM, Stuhtmann G, Meurling S, Lundgren A, Winblad C, Macias Garcia B, Johannisson A. 2014c. Sperm yield after Single Layer Centrifugation with Androcoll-E is related to the potential fertility of the original ejaculate Theriogenology, 81:1005-1011.

Morrell JM, Georgakas A, Lundeheim N, Nash D, Davis-Morel MCG, Johannisson A. 2014d. Effect of heterologous and homologous seminal plasma on stallion sperm quality. Theriogenology 82:176-183.

Morrell JM, Wallgren M. 2014. Alternatives to antibiotics in semen extenders: a review. Pathogens, 3:934-946.

Morrell JM, Sabes Alsina M., Abraham MC, Sjunnesson Y. 2016. Practical applications of sperm selection techniques for improving reproductive efficiency. Anim Reprod, 13:340-345.

Morrell JM, Lagerquist A, Humblot P, Johannisson A. 2017. Effect of single layer centrifugation on reactive oxygen species and sperm mitochondrial membrane potential in cooled stallion semen. Reprod Fertil Dev, 29:1039-1045.

Nongbua T, Johannisson A, Edman A, Morrell JM. 2016a. Effect of bovine seminal plasma on sperm motility and chromatin integrity. Anim Reprod Sci, 169:113-114.

Nongbua T, Yongzhi G, Edman A, Humblot P, Morrell JM. 2016b. Effect of bovine seminal plasma on bovine endometrial epithelial cells proliferation in culture. Theriogenology, 86:348. (Abstract).

Nongbua T, Johannisson A, Edman A, Morrell JM. 2017. Effects of Single Layer Centrifugation (SLC) on bull spermatozoa prior to freezing on post-thaw semen characteristics. Reprod Domest Anim, 52:596-602.

O'Hara L, Forde N, Kelly AK, Lonergan P. 2014. Effect of bovine blastocyst size at embryo transfer on day 7 on conceptus length on day 14: can supplementary progesterone rescue small embryos? Theriogenology, 81:1123-1128.

Ohlweiler LU, Brum DS, Leivas FG, Moyses AB, Ramos RS, Klein N., Mezzalira JC, Parlevliet JM, Colenbrander BC. 1999. Prediction of first season stallion fertility of 3-year-old Dutch Warmbloods with prebreeding assessment of percentage of morphologically normal live sperm. Equine Vet $J$, 31:248-251.

Parlevliet JM, Colenbrander B. 1999. Prediction of first season stallion fertility of 3-year-old Dutch Warmbloods with prebreeding assessment of percentage of morphologically normal live sperm. Equine Vet $\mathrm{J}$. 31:248-51.

Pena FJ, Rodriguez Martınez H, Tapia JA, Ortega Ferrusola C, Gonzalez Fernandez L, Macias Garcia B. 2009. Mitochondria in mammalian sperm physiology and pathology:a review. Reprod Domest Anim, 44:345349.

Rath D, Schuberth HJ, Taylor U. 2008. Sperm interaction from insemination to fertilization. Reprod Domest Anim, 43(suppl. 5):2-11.

Richter J, Stuhtmann G, Martinsson G, Sieme H, Morrell JM. 2016. Stallion sperm survival is increased after colloid centrifugation compared to sperm washing, or extension only, in INRA82 or INRA96. $J$ Equine Vet Sci, 43:S78-S79.

Roca J, Vazquez JM, Gil MA, Cuello C, Parrilla I, Martínez EA. 2006. Challenges in pig artificial insemination. Reprod Domest Anim, 41(suppl. 2):43-53. Rodríguez-Martínez $\mathrm{H}$, Hultgren $\mathrm{J}$, Båge $\mathrm{R}$, Bergqvist A-S, Svensson C, Bergsten C, Lidfors L, Gunnarsson S, Algers B, Emanuelson U, Berglund B, Andersson G, Håård $M$, Lindhé $B$, Stålhamm $H$, Gustafsson H. 2007. Reproductive performance in high-producing dairy cows: can we sustain it under current practice? In: IVIS Reviews in Veterinary Medicine Ithaca NY: International Veterinary Information Service (www.ivis.org). 23 pp. Available on:

https://pub.epsilon.slu.se/3502/1/RodriguezM_etal_090 122.pdf..

Röpke T, Oldenhof H, Leiding C, Sieme H, Bollwein H, Wolkers WF. 2011. Liposomes for cryopreservation of bovine sperm. Theriogenology, 76:1465-1472

Rota A, Furzi C, Panzani D, Camillo F. 2004. Studies on motility and fertility of cooled stallion spermatozoa. Reprod Domest Anim, 39:103-109.

Saini N, Singh MK, Shah SM, Singh KP, Kaushik R, 
Manik RS, Singla SK, Palta P, Chauhan MS. 2015 Developmental competence of different quality bovine oocytes retrieved through ovum pick-up following in vitro maturation and fertilization. Animal, 9:1979-1985.

Schulze M, Ruediger K, Mueller K, Jung M, Wella C, Reissmann M. 2013. Development of an in vitro index to characterize fertilizing capacity of boar ejaculates Anim Reprod Sci, 140:70-76

Seidel GE Jr. 2014. Update on sexed semen technology in cattle. Animal, 8(suppl. 1):160-164.

Shahverdi A, Rastegarnia A, Topraggaleh TR. 2014. Effect of extender and equilibration time on post thaw motility and chromatin structure of buffalo bull (Bubalus bubalis) spermatozoa. Cell J, 16:279-288.

Sjunnesson YC， Morrell JM， González R. 2013. Single Layer Centrifugaction-selected boar spermatozoa are capable of fertilization in vitro. Acta Vet Scand, 55:20-26

Somfai T, Bodo S, Nagy S, Papp AB, Ivancsics J, Baranyai B, Gocza E, Kovacs K. 2002. Effect of swim-up and Percoll treatment on viability and acrosome integrity of frozen-thawed bull spermatozoa. Reprod Domest Anim, 37:285-290.

Stringfellow D, Seidel SM. 1998. Manual of the International Embryo Transfer Society. 3rd ed. Savoy, IL, USA: International Embryo Transfer Society.

Suarez S. 2007. Interactions of spermatozoa with the female reproductive tract: inspiration for assisted reproduction. Reprod Fertil Dev, 19:103-110.

Thys M, Vanadele L, Morrell JM, Mestach J, Van
Soom A, Hoogewijs M, Rodriguez-Martinez H. 2009. In vitro fertilising capacity of frozen-thawed bull spermatozoa separated by colloidal centrifugation through single-layer or gradients. Reprod Domest Anim, 44:390-394.

Trasorras V, Giuliano S, Chaves G, Neild D, Agüero A, Carretero M, Pinto M, Baca Castex C, Alonso A, Rodríguez D, Morrell J, Miragaya M. 2012. In vitro embryo production in Llamas (Lama glama) from in vivo matured oocytes with raw semen processed with Androcoll-e using defined embryo culture media. Reprod Domest Anim, 47:562-567.

Tsakmakidis IA, Lymberopoulos AG, Khalifa TA. 2010. Relationship between sperm quality traits and field-fertility of porcine semen. $J$ Vet Sci, 11:151-4

Underwood SL, Bathgate R, Ebsworth M, Maxwell W.M.C., Evans G. 2010. Pregnancy loss in heifers after artificial insemination with frozen-thawed, sex-sorted, re-frozen-thawed dairy bull sperm. Anim Reprod Sci, 118:7-12

Vandael L,Van Soom A. 2011. Intrinsic factors affecting apoptosis in bovine in vitro produced embryos. Verh K Acad Geneeskd Belg, 73:79-104.

Varner DD, Blanchard TL, Love CC, Garcia MC, Kenney RM. 1987. Effects of semen fractionation and dilution ratio on equine spermatozoa motility parameters. Theriogenology, 28:709-723.

Wiltbank JN, Parish NR. 1986. Pregnancy rate in cows and heifers bred to bulls selected for semen quality. Theriogenology, 25:779-783. 